Original Research Article

\title{
Effect of telmisartan in hypertensive patients with impaired fasting glycaemia
}

\author{
Bheemesh Naidu Mattam ${ }^{1 *}$, Zaheda Bano ${ }^{2}$, A. Meenakumari², V. L. M. Raman ${ }^{2}$
}

${ }^{1}$ Department of Pharmacology, Katuri Medical College, Guntur, Andhra Pradesh, India

${ }^{2}$ Department of Pharmacology, Guntur Medical College, Guntur, Andhra Pradesh, India

Received: 24 April 2017

Accepted: 29 April 2017

*Correspondence to:

Dr. Bheemesh Naidu Mattam,

Email: bheemesh6@gmail.com

Copyright: (C) the author(s), publisher and licensee Medip Academy. This is an openaccess article distributed under the terms of the Creative Commons Attribution NonCommercial License, which permits unrestricted noncommercial use, distribution, and reproduction in any medium, provided the original work is properly cited.

\begin{abstract}
Background: Telmisartan, an angiotensin II receptor blocker, has a higher affinity for AT1 receptors. It has also been recognized as partial agonist of the nuclear hormone receptor PPAR-gamma. The present study is conducted to study the effect of Telmisartan in hypertensive patients with impaired fasting glycaemia.

Methods: This is a prospective and randomised study done on 50 hypertensive patients with impaired fasting glycaemia. All the patients underwent following investigations like Fasting plasma glucose, blood pressure and body mass index were also measured.

Results: Fasting plasma glucose, blood pressure (SBP, DBP) showed significant decrease after intake of $40 \mathrm{mg}$ Telmisartan for three months. Changes in BMI are not significant.

Conclusions: The present study shows that Telmisartan is effective in controlling blood-pressure by its $\mathrm{AT}_{1}$ receptor blocking activity. It is also effective in decreasing fasting blood glucose by its insulin sensitizing activity through partial peroxisome proliferator activated receptor (PPAR) gamma activity.
\end{abstract}

Keywords: Hypertension, Impaired fasting glycaemia, PPAR gamma, Telmisartan

\section{INTRODUCTION}

The epidemiological transition is impelling the developing world towards more non- communicable diseases. ${ }^{1,2}$ Hypertension is one of the leading causes of morbidity and mortality worldwide. ${ }^{3}$ The concomitant occurrence of type 2 diabetes- mellitus leads to a further significant increase in this risk. ${ }^{4}$

It has been observed that patients with hypertension have an increased prevalence of type 2 diabetes mellitus or pre-diabetes (impaired fasting glycaemia and impaired glucose tolerance). ${ }^{5}$

Hypertension, obesity, and diabetes or impaired glucose regulation (impaired fasting glycaemia and impaired glucose tolerance) together constitute the metabolic syndrome. ${ }^{6,7}$
The increasing availability and abundance of highcalorie, low-fiber foods and the adoption of more sedentary lifestyles are all leading to increased prevalence of the metabolic syndrome in developing countries. ${ }^{8}$

Not only hypertensive patients with diabetes, but also hypertensive patients without overt diabetes tend to be resistant to insulin stimulated glucose uptake compared with normotensive people. ${ }^{1}$

It has been observed that about $20 \%$ of patients with hypertension having impaired fasting glycaemia will develop type 2 diabetes in a period of 3 years.

Insulin resistance as predicted by impaired fasting glycaemia is also associated with endothelial dysfunction, which is predictive of future cardiovascular events. 
Some classes of anti-hypertensives, notably angiotensin II receptor blockers (ARBs), have been shown to reduce the incidence of new-onset diabetes. These antihypertensive agents have differential effects in hypertensive patients with impaired fasting glycaemia.

Several recent trials involving patients with hypertension have suggested that Telmisartan, unlike other ARBs, acts as a partial peroxisome proliferator-activated receptorgamma (PPAR $\gamma$ ) agonist at concentrations that are achievable with oral doses. So, it is recommended for the treatment of hypertension with impaired fasting glycaemia, thus suggesting its insulin- sensitizing effect. ${ }^{10,11}$

Based on these studies we undertook a study to demonstrate the effect of telmisartan on blood pressure and blood sugar levels in hypertensive patients with impaired fasting glycaemia.

\section{METHODS}

This was a prospective study, to observe the effect of 40 mg once daily dose of Telmisartan on blood pressure and blood sugar levels in hypertensive patients with impaired fasting glycaemia. The study protocol was approved by institutional ethics committee.

Written informed consent was taken from all the patients. Patients of either sex, aged 25-55 years, who were newly diagnosed mild to moderate essential hypertension (stage1 JNC-7) with impaired fasting glycaemia, attending medical o.p.in Government General Hospital, Guntur were included in this study, after satisfying inclusion and exclusion criteria.

The study was done in 50 patients over a period of 1 year, each patient being followed for 6 months. History, physical examination findings, vital data recordings and relevant laboratory investigation findings of the studied patients were entered in the proforma.

Periodic recording of blood pressure was done every two weeks. Periodic fasting blood sugar levels were done every month.

BMI was measured at the beginning and end of the study. Laboratory investigations were carried out before initiation of therapy and at the end of the study. Blood pressure was measured in the non-dominant hand, in sitting posture after 5 minutes' rest with arm supported at heart level. Sugar levels were measured after 8 hours of overnight fasting.

\section{Inclusion criteria}

- Age- 25 to 55 Years

- Sex-Both sexes
- Newly diagnosed essential hypertension (Stage-1 JNC-7) with Impaired fasting-glycaemia who were willing to give the consent

- Normal liver and kidney function tests.

\section{Exclusion criteria}

- Severe hypertension, Secondary hypertension

- Patients already on other antihypertensive drugs

- Overt diabetes mellitus patients

- Severe obesity $(>35 \mathrm{~kg} / \mathrm{m} 2)$

- Chronic use of corticosteroids, NSAIDS and Oral contraceptives pills

- Any acute illness

- Thyroid disease

- Pregnancy, Lactation.

\section{Investigations done}

- Hemoglobin

- Total count and differential count

- Fasting blood sugar

- Blood urea

- Serum bilirubin

- Serum creatinine

- Complete urine examination-Urine albumin and sugar and microscopic examination

- Microalbuminuria tested with strip method with early morning sample of urine.

Body mass Index (BMI) calculated with formula:

$$
\mathrm{BMI}=\text { Weight in } \mathrm{Kg} / \text { Height in square meters. }
$$

All patients were given $40 \mathrm{mg}$ Telmisartan once daily early in the morning to be taken on empty stomach.

All the patients were advised on increasing physical activity, increase in the intake of low-salt and high fibrediet.

Statistical analysis method employed for analysis of data is Paired ' $t$ ' test used for testing the statistical significance. $\mathrm{p}$ value $<0.01$ is taken as statically significant.

\section{RESULTS}

\section{Patients details}

56 patients were enrolled in the study. Six of them developed diabetes during the study period, hence they were excluded from the study and 50 patients completed the study period.

Out of these 50 patients $54 \%(n=27)$ were males and $46 \%$ $(n=23)$ were females. 
Out of 50 patients, $68 \%(n=34)$ patients belonged to 45 55yrs, $24 \%(\mathrm{n}=12)$ of patients were $35-45$ years, and $8 \%$ $(n=4)$ belonged to 25-35 years of age. Maximum number of patients belonged to 45-55 years (Table 1 ).

Table 1: Patients details.

\begin{tabular}{|ll|}
\hline Patients details & No. of patients $(\mathbf{n}=\mathbf{5 0})$ \\
\hline Gender & \\
\hline Males & $27(54 \%)$ \\
\hline Females & $23(46 \%)$ \\
\hline Age distribution & \\
\hline $25-35$ years & $4(8 \%)$ \\
\hline $35-45$ years & $12(24 \%)$ \\
\hline $45-55$ years & $34(68 \%)$ \\
\hline Body mass index & \\
\hline $18.5-25 \mathrm{Kg} / \mathrm{m}^{2}$ (Normal) & $15(30 \%)$ \\
\hline $25-30 \mathrm{Kg} / \mathrm{m}^{2}$ (Overweight) & $20(40 \%)$ \\
\hline $30-35 \mathrm{Kg} / \mathrm{m}^{2}$ (Obese) & $15(30 \%)$ \\
\hline
\end{tabular}

Out of these 50 patients 15 patients had BMI between 18.5-25 Kg/m2 (normal), 20 patients had BMI between $25-30 \mathrm{Kg} / \mathrm{m}^{2}$ (overweight), 15 had BMI between $30-35$ $\mathrm{Kg} / \mathrm{m}^{2}$ (obese class I).

Investigations shown in (Table 2).

Table 2: Investigations done.

\begin{tabular}{|lll|}
\hline Investigations & $\begin{array}{l}\text { Before treatment } \\
\text { (Mean } \pm \text { St.Dev) }\end{array}$ & $\begin{array}{l}\text { After } \\
\text { treatment } \\
\text { (Mean } \pm \text { St.Dev) }\end{array}$ \\
\hline $\begin{array}{l}\text { Blood pressure } \\
\text { (mm of Hg) }\end{array}$ & \\
\hline Systolic BP & $153.60 \pm 7.49$ & $131.60 \pm 8.65$ \\
\hline Diastolic BP & $91.40 \pm 6.70$ & $80.0 \pm 4.94$ \\
\hline $\begin{array}{l}\text { Fasting plasma } \\
\text { glucose } \\
\text { (mg/dl) }\end{array}$ & $118.56 \pm 3.79$ & $115.04 \pm 4.43$ \\
\hline $\begin{array}{l}\text { Body Mass } \\
\text { Index }\left(\mathrm{kg} / \mathrm{m}^{2}\right)\end{array}$ & $29.24 \pm 4.34$ & $29.05 \pm 4.30$ \\
\hline
\end{tabular}

\section{Systolic BP}

At the initiation of study $153.6 \pm 7.49$ (mean \pm st.dev) $\mathrm{mm}$ of $\mathrm{Hg}$. At the end of 6 months (completion of study) 131.6 \pm 8.65 (mean \pm st.dev) $\mathrm{mm}$ of $\mathrm{Hg}(\mathrm{p}<0.001$, highly significant).

\section{Diastolic BP}

At the initiation of study was $91.40 \pm 6.70$ (mean \pm st.dev) $\mathrm{mm}$ of $\mathrm{Hg}$. At the end of 6months (completion of study) was $80.0 \pm 4.94$ (mean \pm st.dev) $\mathrm{mm}$ of $\mathrm{Hg}(\mathrm{p}<0.001$, highly significant).

\section{Fasting plasma glucose}

At the initiation of study was $118.56 \pm 3.79$ (mean \pm st.dev).
At the end of 6 months (completion of study) FPG was $115.04 \pm 4.43$ (mean \pm st.dev) $\mathrm{mg} / \mathrm{dl}$ ( $\mathrm{p}<0.001$, highly significant).

\section{Body mass index (BMI)}

At the initiation of study mean BMI was 29.24 \pm 4.34 (mean \pm st.dev) $\mathrm{Kg} / \mathrm{m}^{2}$. At the end of 6 months (completion of study) was 29.05 \pm 4.30 (mean \pm st.dev) $\mathrm{Kg} / \mathrm{m}^{2}$.

There is statistically very high significant change ( $p$ $<0.001$ ) found in the levels of both blood pressure and fasting plasma glucose levels in the patients.

The difference in the levels of mean BMI before and after the study period is not statistically significant ( $p$ value $0.16)$.

\section{Adverse effects}

One patient who developed dry cough was treated with anti-tussives and continued in the study. One patient developed mild rash and was treated with anti-histamines and continued in the study.

\section{DISCUSSION}

The results in the present study suggested that Telmisartan 40mg once daily was effective in reducing blood pressure and fasting plasma glucose levels from the base line, in hypertensive patients with Impaired fasting glycaemia. The results are highly statistically significant $(\mathrm{p}<0.001)$ in the reduction of both blood pressure and fasting plasma glucose levels in the patients.

In this present study, the decrease in blood pressure and fasting glycaemia are consistent with the results of Cristiana et al. Metabolic effect of telmisartan and losartan in hypertensive patients with metabolic syndrome $\mathrm{m}^{7}$ - concludes that besides providing superior 24hour blood pressure control, Telmisartan unlike Losartan displays insulin sensitizing activity, which may be explained by its partial PPAR gamma activity.

Masaki et al found the effect of Telmisartan on insulin resistance in Japanese type 2 diabetes mellitus- in which it was concluded that blood pressure levels and fasting plasma glucose levels, reduced significantly following treatment with Telmisartan. ${ }^{6}$ According to Thomas Unger preclinical effect of RAS inhibition with a focus on telmisartan. Telmisartan is the only ARB that may modulate PPAR $\gamma$ activation at physiological concentration, as an effect that is likely to be related to Telmisartan high lipophilicity and long plasma half-life among all ARBs. ${ }^{10}$

The present results can also be reinforced with Bahr IN et al, high-dose treatment with telmisartan induces monocytic peroxisome proliferators-activated receptor- $\gamma$ 
target genes in patients with the metabolic syndrome which demonstrates its role in positive actions on lipid and glucose metabolism prevention of new onset of diabetes. $^{12}$ No serious adverse effects were observed during the study period. After completion of the study period (6months), patients were advised to continue antihypertensive medication and life style changes like increasing physical activity, intake of low salt and highfibre diet.

\section{CONCLUSION}

Telmisartan is effective in controlling blood-pressure by its AT1 receptor blocking activity. It is also effective in decreasing fasting blood glucose by its insulin sensitizing activity through partial peroxisome proliferator activated receptor (PPAR) gamma activity. Patients showed good compliance on treatment with Telmisartan, due to its dual beneficial actions and less adverse effects. Further studies with large sample size and longer follow up are required to confirm the findings of the present study.

\section{ACKNOWLEDGMENTS}

Authors would like to thank the patients, all the faculty and supporting staff who helped me in carrying my study.

Funding: No funding sources Conflict of interest: None declared

Ethical approval: The study was approved by the Institutional Ethics Committee

\section{REFERENCES}

1. Akintunde AA, Epidemilogy of conventional cardiovascular risk factor among hypertensive subjects with normal and impaired fasting glucose. SAMJ. 2010;100(9):594.

2. Yusuf S, Reddy S, Dompao S. Global burden of cardiovascular disease Part I. General considerations, the epidemiologic transition, risk factor and impact of urbanization. Circulat. 2001;104:2746-53.
3. Whitworth JA. $2003 \mathrm{WHO} /$ International Society of Hypertension (ISH) Statement on management of hypertension. J Hypert. 2003,21:1983-1992.

4. Heikes KE, Eddy DM, Arondekar B, Schlessinger L. Diabetes risk calculator. Diab Care. 20081;31(5):1040-5.

5. Watanabe M. Effect of telmisartan on insulin resistance in Japanese type 2 diabetic patients. Intern Med. 2010;49:1843-7.

6. Vitale C, Mercuro G, Castiglioni C, Cornoldi A, Tulli A, Fini M, et al. Metabolic effect of telmisartan and losartan in hypertensive patients with metabolic syndrome. Cardiovascular Diabetology. 2005;15;4(1):6.

7. Wofford MR, King DS. Deborah SK. Relationship between antihypertensive drugs and metabolic syndrome. Metab Syndr Relat Disord. 2004;2(4):30814.

8. Report of the expert committee on the diagnosis and classification of diabetes mellitus. Diab Care. 1997;20:7:1183-97.

9. Unger T. Preclinical and clinical effects of RAS inhibition with a focus on telmisartan. ISRN Vascular Medicine. 2012;2012.

10. Kurtz TW. Anti-diabetic mechanism of angiotensin converting enzyme inhibitors and angiotensin receptor antagonists: beyond the rennin-angiotensin system. J Hypert. 2004;22(12)2253-61.

11. Henry P. Impaired fasting glucose, blood pressure and cardiovascular disease mortality. Hypert. 2002;40:458-63.

12. Bähr IN, Tretter P, Krüger J, Stark RG, Schimkus J, Unger $\mathrm{T}$ et al. High-dose treatment with telmisartan induces monocytic peroxisome proliferator-activated receptor- $\gamma$ target genes in patients with the metabolic syndrome. Hypert. 2011;58(4):725-32.

Cite this article as: Mattam $\mathrm{BN}$, Bano Z, Kumari AM, Raman VLM. Effect of telmisartan in hypertensive patients with impaired fasting glycaemia. Int J Basic Clin Pharmacol 2017;6:12614. 